\title{
Doctors left to define foreseeable death in new law
}

W hat does "reasonably foreseeable death" mean? A month? Six? Two years? This is the question medical groups, physicians' insurer and regulators are asking following the June 17 passage of a law allowing physician-assisted dying.

There's potentially a lot at stake: if doctors get it wrong, they could face criminal charges. The Canadian Medical Protective Association (CMPA) recommends its physician members call them for advice about all requests for physician-assisted dying. "If death is not reasonably foreseeable we would indicate that issue and tell you that if you proceed you leave yourself open to criminal sanctions," said CMPA's associate executive director, Doug Bell.

Defining the term is an issue Canada's 13 regulatory colleges must consider as they revamp guidelines in accordance with the new legislation. But it's also a question the federal ministries of health or justice could answer. No one has so far.

Canada isn't the first country or jurisdiction to legalize physicianassisted dying, but it is the first to introduce a wide-ranging bill over such a geographically large area. Bill C-14 amends the Criminal Code to remove prohibitions against assisted dying and establishes national guidelines with strict safeguards concerning who is eligible for assisted death, as well as outlining the process. Eligibility requires, among other things, clear consent from a competent adult whose death is reasonably foreseeable. The process includes safeguards such as having two independent witnesses and medical opinions.

The House of Commons initially approved the bill on June 3; the Senate then proposed seven amendments. The House accepted most of those, including agreeing that the federal government would hold a consultation on palliative care options, and an amendment banning beneficiaries from signing consent forms on behalf of

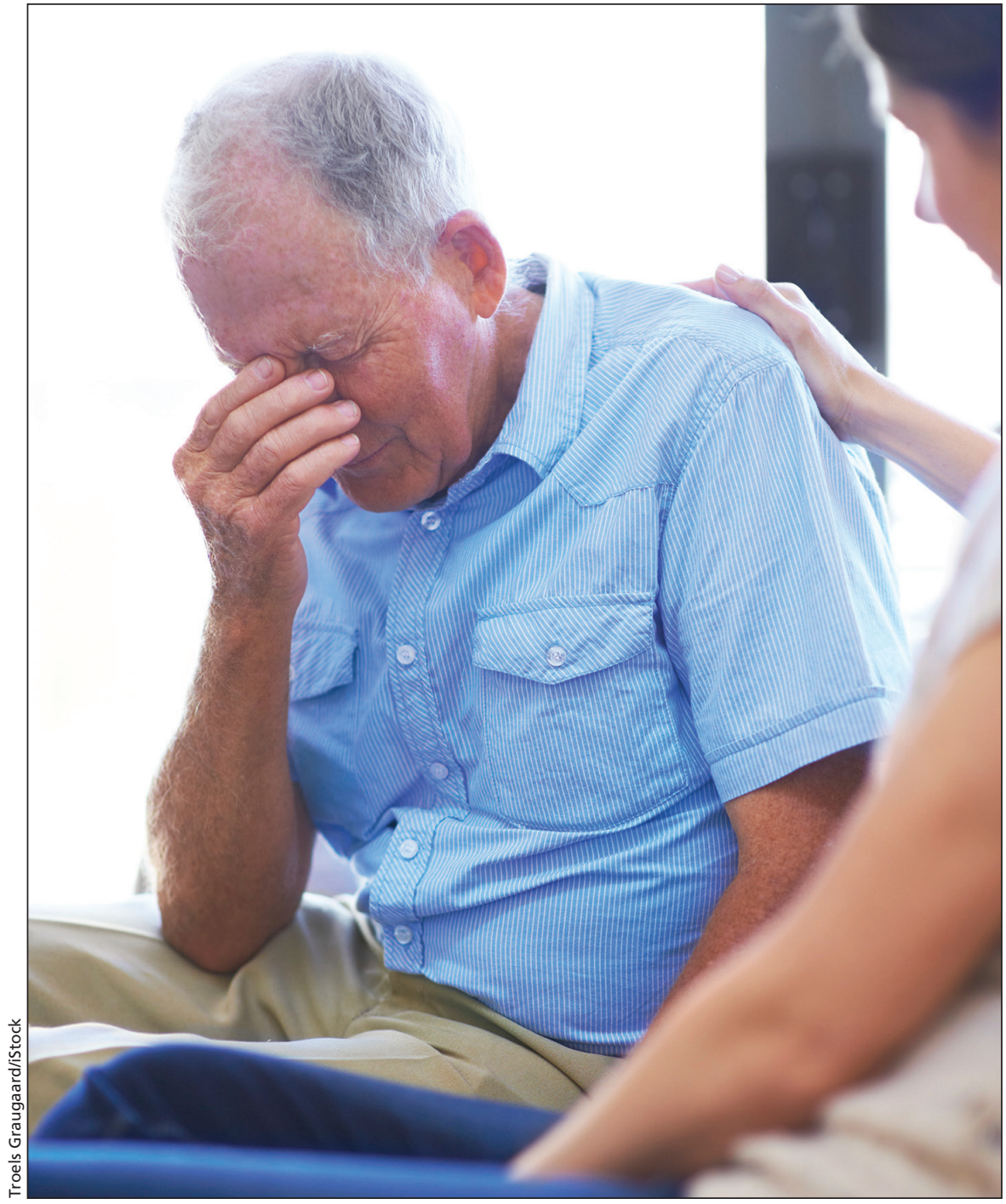

Canadian physicians must figure out how to apply the new assisted-dying law, including defining reasonably foreseeable death.

patients. But the House refused to accept the most contentious proposal, which would have removed the "reasonably foreseeable" definition, a change that would have made the law in line with the Supreme Court's ruling that patients suffering from a "grievous and irremediable" medical condition be eligible for assisted death.

In the end, the Senate gave in to the elected House and passed the bill; royal assent came within two hours.

Medical colleges are now revising guidelines to meet the new legislative requirements. Some provinces, including Alberta and Ontario, have also created registries of physicians willing to provide the service.

Creating a consistent way for Canadians to access medical assistance in dying will require the work of the federal and provincial/territorial governments, says Dr. Jeff Blackmer, CMA's vice-president, medical professionalism. Creating registries of willing providers is also important because if physicians have moral objections to providing the 
service, they must be able to point patients to another source.

Doctors are also obligated to at least discuss options if a patient approaches them, Blackmer adds. "We've been very clear that physicians can't simply turn away patients. You can't refuse to have that conversation."

The federal government has been working with the provinces and territories to coordinate end-of-life assistance, stated a spokesperson for Health Canada in an email. "Such a system would help connect patients with a physician or nurse practitioner (if applicable in their province or territory) willing to provide medical assistance in dying. It would also respect the privacy of all individuals, regardless of whether they are seeking or are willing to provide this assistance," Eric Morrissette, assistant chief, media relations, said.

As a first step, patients and providers can find information about medical assistance in dying at www.canada.ca and 1-800-0-Canada, Morrisette wrote.

But even as governments try to set up registries, the vagueness of the term "reasonably foreseeable death" is a "significant concern," Fleur-Ange Lefebvre, executive director and CEO of the Federation of Medical Regulatory Authorities of Canada (FMRAC), said in an email. The federation does not know how to define the term, she added.

In its May submission to the Senate Standing Committee on Legal and Constitutional Affairs, the federation stated that "In the absence of clear language, physicians will be reluctant to act." The inability of physicians to confidently determine eligibility may be a barrier to access, the federation added.

Clearly, physicians will need guidance on what reasonably foreseeable means from either the colleges or the ministries of health and justice, said Bell at the CMPA, which provides medical liability protection for more than 92000 Canadian doctors. He acknowledges that it will take some time for the colleges to update guidelines.

In hearings before a House committee, Bell said the Committee floated the idea that foreseeable might mean six months to two years; but that quantitative guidance failed to make it into the bill.

Clearly, the majority of patients who request assistance in dying will be close to death, due to cancer or other terminal illnesses, Bell said. But then there are those cases, such as a patient who is parapalegic, where death is not necessarily foreseeable.

The term "foreseeable death doesn't have a lot of meaning for physicians," adds Dr. James Downar, a bioethicist and palliative-care physician at the University Health Network in Toronto. "Anybody alive has a foreseeable death, especially someone with a grievous illness." He says the clause adds nothing to the definition, and may be the basis for a legal challenge, given that it isn't in keeping with the Carter v. Canada Supreme Court decision.

He says the law will "undoubtedly" be appealed.

"Absolutely," agrees Dr. Monica Branigan, head of the Canadian Society of Palliative Care Physicians' working group on physician-hastened death. Meanwhile, the uncertainty around the clause may deter physicians from taking part, she says.

\section{Palliative consultation}

The law's call for mandatory consultation with a palliative-care physician also concerns Branigan and the society. "By making it mandatory, the palliative-care physician becomes a gatekeeper to the service. Many palliative-care physicians don't want that role," says Branigan, who practises at The Temmy Latner Centre for Palliative Care at Mount Sinai Hospital in Toronto.

No other jurisdiction in the world has this sort of mandatory consultation, she says.

There's also a limited supply of palliative-care physicians - some 350 in Canada. "Is this the best way to use them?" she asks. It would be better to give any patient who wants to hasten death access to a palliative-care physician if they want it, she says.

It doesn't mean palliative-care physicians don't want to be involved, she adds. "There are $26 \%$ of our members who say they could imagine participating in some way. We do feel we have an active role to play but not in assessing eligibility or being a gatekeeper. We should be assessing suffering."

But participating might be a problem for society members who are conscientious objectors. In a 2015 survey, $75 \%$ of respondents said physicianassisted suicide should not be provided by palliative-care physicians.

"They are concerned about being called in for an assessment that would give a green light to physician-assisted dying," says Downar. "They are being put in a position of what they feel might be facilitation."

\section{Further study}

The bill calls for further study to look at expanding eligibility to include mature minors, advance consent for those losing capacity and those with primary mental illness. A parliamentary review of the law's provisions and the state of palliative care will begin in five years.

The Canadian Medical Association (CMA) stated in a media release that it will soon offer education to physicians so they can "understand and respond appropriately to end-of-life care wishes of patients."

Passage of the bill is a milestone, stated CMA President Dr. Cindy Forbes. It addresses concerns about vulnerable patients who might prematurely end their lives. Forbes cautioned that there is much work to be done to improve access to palliative care.

The law represents a huge change, agrees Branigan. "You're not going to get it right the first time." - Barbara Sibbald, $C M A J$

CMAJ 2016. DOI:10.1503/cmaj.109-5293 